\title{
Cluster de Ventiladores \\ EM CatAnduva
}

FAN INDUSTRY CLUSTER IN CATANDUVA

FER NANDO C. DE ALMEIDA Professor pesquisador da FEA/USP. PhD em Administração de Empresas pela École Supérieure des Affaires de Grenoble - França.

Av. Prof. Luciano Gualberto, 908 - Sala G - 124 São Paulo - SP - 05508-900

E-mail:fcalmeida@usp.br

LUCIANA M. ONUSIC

Professora da FCECA da Universidade Presbiteriana Mackenzie. Mestranda FEA/USP. Rua Chapéu de Sol, 208 Cotia - São Paulo - 06706-250

E-mail: lucianaonusic@mackenzie.com.br

AMAURY P. GREMAUD

Professor pesquisador da FEA-RP/USP.

Doutor pelo Departamento de Economia da FEA/USP.

Av. dos Bandeirantes, 3900

Ribeirão Preto - São Paulo - 14040-900 E-mail: agremaud@usp.br 


\section{RESUMO}

Este trabalho apresenta os resultados de um levantamento feito na cidade de Catanduva sobre a indústria de ventiladores nela instalada. É, inicialmente, apresentado o conceito de cluster, para, em seguida, serem apresentadas as características do setor de ventiladores de Catanduva, fazendo uma comparação desse setor com o conceito de cluster. Diversos aspectos mostram o interesse em considerar o setor como um cluster e são feitas sugestões para seu aprimoramento.

\section{PALAVRAS-CHAVE}

Cluster; Indústria de ventiladores; Desenvolvimento local.

\section{ABSTRACT}

This paper presents the results of a study developed in the city of Catanduva about the industry of fans installed in the city. At the beginning of the study is presented the concept of industrial clusters to explore the characteristics of this industry in Catanduva, confronting this region with the concept of cluster. Many aspects show the interest in observing this sector as a cluster and some suggestions are made to its development.

\section{KEYWORDS}

Cluster; Air conditioners industry; Local development. 


\section{INTRODUÇ ÃO}

Nos últimos anos, tem havido um crescente interesse no estudo de aglomerados industriais (clusters), em razão do potencial competitivo de regiões produtivas que se configura a nesse tipo de organização.

Esses aglomerados industriais destacam-se como forma competitiva importante, em particular em países em desenvolvimento como o Brasil, dando a possibilidade de desenvolvimento de economias locais e regionais e principalmente possibilitando atingir competitividade em escala mundial. Pequenas e médias empresas de um aglomerado industrial alcançam escala global em sua atuação, o que seria em muitos casos impensável se atuassem de maneira isolada.

Aparece nos clusters uma eficiência como combinação de ações coletivas não planejadas e planejadas, destacando-se sua importância para pequenas e médias empresas (SCHMITZ, I997, I999).

No cenário atual, com a globalização acelerando a velocidade com que ocorrem fusões, incorporações e centralizações, formando um ambiente claramente propício para as grandes empresas, as pequenas e médias empresas pareciam tender à extinção. Esboçam-se, no entanto, os clusters como uma forma de reação (AMATO NETO, 2000).

Este trabalho estuda uma concentração de atividades na cidade de Catanduva em torno da produção de ventiladores, o que leva a avaliar a hipótese de considerála como um cluster, o cluster de produção de ventiladores. A cidade é conhecida como a capital dos ventiladores de teto (SUZIGAN et al., 2000). É feita, neste trabalho, uma revisão do conceito de cluster na literatura, para em seguida explorar a produção de ventiladores em Catanduva. As características de um cluster são relacionadas por meio da revisão da literatura, gerando a proposta de um referencial de observação das características de um cluster. Com base nas entrevistas feitas com empresários da região, as características de um cluster, existente ou potencial, nesse aglomerado industrial são identificadas e discutidas. O aglomerado de Catanduva é então confrontado com o referencial de observação. Finalmente são discutidas ações possíveis de serem implementadas no aglomerado de Catanduva.

O conceito de cluster pode estar voltado a empresas, a uma região ou a uma nação. Para Porter (I999), é importante obter vantagem competitiva por meio do fortalecimento de regiões e nações. Segundo esse autor, a competitividade das nações e das regiões está baseada em sua capacidade de inovação e melhoria contínua.

Segundo Conejos et al. (1997), identificar fontes de vantagem competitiva e formas ideais de combiná-las, para realçar a competitividade das empresas, supõe analisar as habilidades e o conhecimento existente em uma zona geográfica concreta.

$\mathrm{Na}$ economia atual, as decisões de investimento estão cada vez mais condicionadas por essas vantagens competitivas dinâmicas, como existência de uma 
infra-estrutura local adequada, proximidade de centros de pesquisa e desenvolvimento, oferta de mão-de-obra qualificada e acesso aos modernos meios de transporte e de comunicações (AMATO NETO, 2000).

A crescente importância que esse tema vem tomando justifica-se por termos no Brasil uma infinidade de micros, pequenas e médias empresas que, além de empregarem um considerável percentual da mão-de-obra, ainda contribuem de maneira acentuada para a formação do PIB brasileiro (AMATO NETO, 2000).

É importante destacar o papel do governo no desenvolvimento desses aglomerados. O País tem então interesse no desenvolvimento desses clusters, que devem ser estimulados por ações governamentais. As forças de mercado, segundo Porter (I999), são responsáveis pela determinação de um cluster, mas o governo tem papel de responsabilidade pela educação, infra-estrutura física e regras de concorrência no cluster. Segundo Scott (I998), as políticas públicas são essenciais para o desenvolvimento e obtenção de competitividade desses aglomerados.

\section{AGLOMERADOS INDUSTRIAIS OU CLUSTERS}

O entendimento dos aglomerados industriais existentes passa pelo entendimento da definição do que são esses aglomerados. Este texto está dividido em duas partes. Em uma primeira parte, percorre-se a literatura existente, no sentido de entender como diversos autores definem e explicam a existência dos clusters. Na segunda parte, destaca-se o cluster pesquisado.

Porter (I998:78) define cluster da seguinte forma:

Clusters são concentrações geográficas de companhias e instituições inter-relacionadas num setor específico. Os clusters englobam uma gama de empresas e outras entidades importantes para a competição, incluindo, por exemplo, fornecedores de insumos sofisticados, tais como componentes, maquinário, serviços e fornecedores de infraestrutura especializada. Os clusters, muitas vezes, também se estendem para baixo na cadeia produtiva até os consumidores, e lateralmente até manufaturas de produtos complementares e na direção de empresas com semelhantes habilidades, tecnologia, ou mesmo de insumos. Finalmente, muitos clusters incluem órgãos governamentais e outras instituições - tais como, universidades, agências de padronização, "think tanks", escolas técnicas e associações de classe - que promovem treinamento, educação, informação, pesquisa e suporte técnico. 
Enright (1992, I993) define que cluster regional é a reunião de empresas de uma mesma atividade ou relacionada em um determinado espaço geográfico. Sforzi (I992) define um distrito industrial como uma concentração de indústrias que estão envolvidas em processos de produção interdependentes e têm proximidade geográfica - distância inferior a uma viagem diária de trabalho, segundo o autor.

O Competitiveness Institute (2000) destaca nos clusters a existência de empresas que estão relacionadas devido ao desenvolvimento e à utilização de tecnologias comuns e a sistemas de produção que podem envolver diversas empresas de diferentes portes. Segundo esse instituto, distritos industriais agrupam indústrias de um único ramo de atividade, enquanto os clusters regionais não se restringem a um único setor.

Um cluster é uma aglomeração de tamanho considerável de firmas com perfil de especialização e comércio interfirmas substancial (ALTENBURG e MEYER-STAMER, I999), sendo que suas fronteiras são determinadas pelas ligações e pela interdependência entre os diversos setores e instituições, podendo ultrapassar fronteiras estaduais ou nacionais (PORTER, I999).

Os clusters se caracterizam por apresentar um conjunto de empresas que usufrui atividades complementares e estabelecem vínculos por meio da interação entre clientes, tecnologias e canais de distribuição (GRAINO, I998).

Os clusters em países em desenvolvimento utilizam-se de maior integração vertical, dependem de componentes e tecnologias de outros lugares e não encontram tantos problemas de comunicação, relacionamentos e oferta de mão-de-obra especializada, como é o caso em muitos países em desenvolvimento (PORTER, I998).

O caráter dinâmico dos clusters faz com que as empresas necessitem estar constantemente atualizadas. O ambiente em que estão inseridos envolve simultaneamente concorrência e cooperação, o que estimula seu desenvolvimento (PORTER, I998).

Suzigan et al. (2000) destacam o que se deve esperar encontrar em um cluster: concentração de mão-de-obra e tecnologia, interação por meio de linkagens de produção, comércio de distribuição, cooperação em marketing, promoção de exportações, atividades de P\&D e um "saudável equilíbrio entre competição e cooperação".

\section{JUSTIFICATIVAS DA EXISTÉNCIA DE UM CLUSTER}

Um cluster pode ser visto como uma forma alternativa de organização de uma cadeia de valor, a proximidade física das empresas e das instituições, bem como as recorrentes trocas existentes entre elas, facilita bastante a coordenação e aumenta 
a confiança mútua. Vale ressaltar que as principais vantagens de um cluster são a eficiência e a flexibilidade que ele promove às empresas que dele fazem parte.

Porter (I999) destaca três aspectos que fazem com que os clusters afetem a capacidade de competição das empresas:

- aumento da produtividade das empresas sediadas na região;

- direção e ritmo da inovação, que sustentará o aumento da produtividade; e

- estímulo da formação de novas empresas, o que poderá expandir o próprio cluster.

O autor destaca, ainda, uma série de fatores que diferenciam a atuação de um cluster de empresas em relação a uma atuação isolada: maior eficácia na compra de insumos, relacionamento mais próximo e eficiente com fornecedores com melhor comunicação, redução de custos de transação com gerenciamento de estoques e eficiência na entrega. Em razão da especialização e proximidade, os clusters têm vantagens na facilidade de contratação de mão-de-obra, no acesso a tecnologias e informações, na interação com empresas complementares.

Os clusters permitem a obtenção do que Schmitz (I995) chama de eficiência coletiva gerada de maneira espontânea ou planejada. O autor define eficiência coletiva como vantagem competitiva oriunda de economias externas locais por meio de ações conjuntas. Economias externas são subprodutos obtidos não intencionalmente, ou incidentalmente, por meio de ações econômicas (McCORMICK, I998). As ações conjuntas no sentido de cooperação (entre empresas, por intermédio de associações, sindicatos, centros de pesquisa, entre outros) geram economias externas e aumentam a competitividade de um cluster.

Segundo Porter (I999), a dinâmica de uma região, em torno de um setor de atividades, propicia o aparecimento de novas empresas dentro de clusters, preferencialmente, em regiões isoladas, pois são mais perceptíveis as lacunas que existem em termos de produtos e serviços, além de o novo empreendedor poder tirar proveito das relações já estabelecidas no cluster.

A existência de um cluster pode estimular a participação do governo, justificando os investimentos em infra-estrutura ou educação em uma região de atividade homogênea. Parcerias e cooperação entre governo e empresas do setor privado se tornam propícias (SCHMITZ, I997, I999; PORTER, I999).

Segundo Audretsch (I998), a organização em cluster estimula a inovação, uma vez que a proximidade local facilita o fluxo de informação e a geração de benefícios não planejados ou não intencionais para outros integrantes do cluster (spill over).

Um cluster pode surgir de várias formas, como por meio de um funcionário que sai de uma empresa e inicia uma outra empresa com a mesma atividade. Isso foi exatamente o que ocorreu no setor de ventiladores em Catanduva. Podese sintetizar o interesse sobre os cluster discutidos na literatura com base na Tabela I, que destaca as características de uma organização em formato de cluster em relação à atuação isolada de uma empresa em uma atividade econômica. 
TABELA I

CLUSTER VERSUS ATUAÇÃO DE

UMA EMPRESA FORA DE UM CLUSTER

\begin{tabular}{|c|c|c|}
\hline Características & Cluster & Empresa isolada \\
\hline Mão-de-obra & Disponível na região (PORTER, 1999) & $\begin{array}{l}\text { Pode necessitar procurá-la fora da } \\
\text { região }\end{array}$ \\
\hline Tecnologia & $\begin{array}{l}\text { Desenvolvida por meio de parcerias } \\
\text { entre empresas (WEVER e SATM, 1999; } \\
\text { CAMAGNI, 1991;AUDREST, 1998) }\end{array}$ & Desenvolvida pela empresa \\
\hline Tipo de coordenação & Dinâmica de mercado (PORTER, 1999) & Coordenação hierárquica \\
\hline Custos de coordenação & $\begin{array}{l}\text { Apesar da dinâmica de mercado, ten- } \\
\text { dem a ser reduzidos em razão da proxi- } \\
\text { midade e intimidade desenvolvida entre } \\
\text { os parceiros (fornecedores e clientes) - } \\
\text { (NOOTEMBOMM, 1992) }\end{array}$ & $\begin{array}{l}\text { Menores por se estruturar de maneira } \\
\text { hierárquica }\end{array}$ \\
\hline Custos de produção & Maior eficiência (HANSEN, 1992) & $\begin{array}{l}\text { Menor eficiência em função da estrutura } \\
\text { hierárquica }\end{array}$ \\
\hline Exposição a forças competitivas & $\begin{array}{l}\text { Maior (PORTER, 1998; SUZIGAN et al., } \\
\text { 1999) }\end{array}$ & Pode ser menor \\
\hline Impacto nos preços & $\begin{array}{l}\text { Os preços tendem a ser menores em } \\
\text { razão da concorrência entre empresas } \\
\text { no cluster }\end{array}$ & $\begin{array}{l}\text { Variável em função da concorrência nos } \\
\text { mercados consumidores }\end{array}$ \\
\hline $\begin{array}{l}\text { Comunicação com } \\
\text { fornecedores e clientes }\end{array}$ & $\begin{array}{l}\text { Facilitada pela comunicação pessoal } \\
\text { (HAKANSSON, 1993; KAMANN, 1998; } \\
\text { PORTER, 1999) }\end{array}$ & $\begin{array}{l}\text { Dificultada em razão das eventuais } \\
\text { distâncias }\end{array}$ \\
\hline Apoio governamental & $\begin{array}{l}\text { Estimulado por se tratar de investimen- } \\
\text { tos em uma região econômica } \\
\text { (SCHMITZ, 1997, 1999; SCOTT, 1998; } \\
\text { PORTER, 1999) }\end{array}$ & $\begin{array}{l}\text { Inibido quando se trata de privilegiar } \\
\text { empresas isoladas }\end{array}$ \\
\hline Investimentos em formação e educação & Compartilhados pelas diversas empresas & $\begin{array}{l}\text { Assumidos pela empresa (exemplo de } \\
\text { escolas criadas pelas próprias empresas) }\end{array}$ \\
\hline Surgimento de novos concorrentes & $\begin{array}{l}\text { Facilitado em função da atração de } \\
\text { pequenos empresários especializados } \\
\text { (PORTER, 1999) }\end{array}$ & $\begin{array}{l}\text { Existência de barreiras à entrada em razão } \\
\text { de necessidades de ganhos de escala. }\end{array}$ \\
\hline Eficiência coletiva e cooperação & $\begin{array}{l}\text { Obtida por meio de ações de cooperação } \\
\text { entre empresas (SCHIMTZ, 1997, 1999; } \\
\text { PORTER, 1998; GEINDRE, 2001) }\end{array}$ & $\begin{array}{l}\text { Dificuldade em razão da coordenação } \\
\text { dirigida de maneira hierárquica e centra- } \\
\text { lizada. }\end{array}$ \\
\hline Economias de Escala & $\begin{array}{l}\text { Tanto na exploração de um mercado } \\
\text { mais extenso, quanto no compartilha- } \\
\text { mento de maquinário e outros fatores } \\
\text { de produção (McCORMICK, 1998). }\end{array}$ & $\begin{array}{l}\text { Uma empresa isolada em produção ver- } \\
\text { tical deve maximizar a escala de seu } \\
\text { mercado para otimizar o uso de seus } \\
\text { recursos de produção. }\end{array}$ \\
\hline
\end{tabular}

Fonte: Elaborada pelos autores com base na revisão da literatura. 
Como destaca a Tabela I, em muitos casos a existência de um cluster apresenta vantagens em relação a empresas isoladas, tais como desenvolvimento de tecnologia por meio de parcerias, redução de custos de coordenação e de produção, facilidade de comunicação entre fornecedores e clientes, compartilhamento de investimentos em formação e educação em razão da proximidade das empresas e da exposição às forças competitivas. Destaca-se também a exposição à concorrência, que gera impacto nos preços. Pode-se observar uma eficiência coletiva pela cooperação entre empresas e finalmente economias de escalas por meio da exploração de um mercado maior ou no compartilhamento de maquinário e de outros fatores de produção.

Outro aspecto importante, na discussão da hipótese de Catanduva como um cluster, é avaliá-lo pela discussão conceitual na literatura sobre as razões da existência de um cluster. Wever e Stam (I999) apresentam a justificativa da existência de um cluster, por meio de um conjunto de teorias desenvolvidas na literatura.

O primeiro aspecto diz respeito à abordagem da economia de aprendizado, que, construída, a partir de Schumpeter, é baseada na idéia de que inovações é resultado de um processo de interação entre clientes, fornecedores e centros de conhecimento. Como conseqüência, a proximidade desses atores facilita o processo de inovação (WEVER E STAM, I999).

Por outro lado, a abordagem de rede (HAKANSSON, I993; KAMANN, I998) considera a estabilidade das relações pessoais como fator determinante do sucesso dos atores, o que reforça o interesse da proximidade entre eles.

Nootemboom (I992) enfatiza a abordagem dos custos de transação, em que em particular a capacidade de inovação está influenciada pelos custos de transação e distância, que nos clusters são menores. O autor destaca que os clusters são especialmente interessantes na primeira fase do ciclo de inovação, em que a transmissão de conhecimento tácito requer proximidade a fim de evitar grandes custos de transação.

Segundo Audrestsch (I998), atividades em torno de um novo conhecimento tendem a aglomerar-se em uma região geográfica, o que permite uma maior interação entre os empreendedores no desenvolvimento desse novo conhecimento.

A geração de economia de escala é outro fator que favorece a criação de clusters (McCORMICK, I998). Pode estar relacionada ao tamanho do mercado, mas também a investimentos em maquinário e oportunidades de divisão de trabalho na produção. Segundo a autora, observam-se aumentos nos retornos da atividade quando cada aumento na quantidade de insumos gera um aumento proporcional, ou maior ainda, nos outputs. Os ganhos de escala permitem alcançar essa proporcionalidade.

Camagni (I99I) considera que as pequenas e médias empresas (PMEs), sendo incapazes de inovar isoladamente, são levadas a trabalhar em conjunto. Nesse sentido, Hansen (I992) afirma que a proximidade de concorrentes, fornecedores e clientes, além de estimular a eficiência, propicia também a inovação. 
Suzigan e colaboradores (2000) classificam o surgimento de clusters com base em dois enfoques. No primeiro enfoque o cluster surge como resultado natural das forças de mercado. É a visão apresentada por Krugman (I998) e Porter (I998). No segundo enfoque, o cluster surge e cresce por meio de esforços ativos do setor público e da cooperação entre as empresas. É a visão de Scott (I998), Audretesch (1998) e Schmitz (I997, I999).

\section{MÉTODO DE PESQUISA}

Esta pesquisa, de caráter exploratório, foi desenvolvida utilizando-se duas fontes de dados. A primeira foi a identificação de características da atividade econômica de Catanduva a partir das bases de dados da Rais. Com esses dados, pôde-se observar de que maneira se distribui a atividade industrial na região, bem como identificar os graus de especialização por meio do cálculo de índices de especialização (SUZIGAN e colaboradores, 2000) avaliando a existência de concentração de atividades em torno da produção de ventiladores em Catanduva. O cálculo do índice de especialização é dado pela relação entre empregos gerados no setor no município e o total de empregos gerados no município, e a relação dos empregos gerados no setor no Estado e o total de empregos gerados no Estado, conforme a Equação I.

\section{EQUAÇ̃̃O I}

\section{ÍNDICE DE ESPECIALIZAÇÃO}

$$
I_{i}=\frac{\mathrm{NL}_{\mathrm{i}, \mathrm{A}} / \sum_{\mathrm{i}=1}^{\mathrm{n}} \mathrm{NL}_{\mathrm{i}, \mathrm{A}}}{\mathrm{NL}_{\mathrm{i},} / \sum_{\mathrm{i}=1}^{\mathrm{n}} \mathrm{NL}_{\mathrm{i},}}=\text { índice de especialização }
$$

$$
\begin{aligned}
& \mathrm{NL}_{\mathrm{i}, \mathrm{A}}=\mathrm{n}^{0} \text { empregados no setor/na microrregião } A \\
& \sum_{\mathrm{i}=1}^{\mathrm{n}} \mathrm{NL}_{\mathrm{i}, \mathrm{A}}=\mathrm{n}^{0} \text { empregados em todos os setores na microrregião } A \\
& \sum_{\mathrm{i}=1}^{\mathrm{NL}} \mathrm{NL}_{\mathrm{i},} \quad=\mathrm{n}_{\mathrm{i},}=\mathrm{n}^{\mathrm{o}} \text { empregados no setor/no Estado }
\end{aligned}
$$


A segunda fonte de dados foi a realização de entrevistas com empresários da região, buscando detalhar as características da atividade desenvolvida no setor. A Tabela I, exibida na primeira parte do texto, que apresenta as características de um cluster, é então confrontada às características identificadas no aglomerado industrial de Catanduva.

\section{CLUSTER DE CATANDUVA}

O município de Catanduva possui pouco mais de roo mil habitantes e se localiza no interior do Estado de São Paulo, a aproximadamente $450 \mathrm{~km}$ da capital. Em comparação com outras cidades do interior paulista, possui um volume significativo de pessoas empregadas formalmente no setor industrial, conforme mostra a Tabela 2 . Um total de 242 estabelecimentos industriais preencheu a guia da Rais em 1998 (veja a Tabela 3).

\section{TABELA 2}

NUMERO DE EMPREGADOS FORMAIS POR SUBSETOR IBGE, MUNICÍPIO DE CATANDUVA, I99I, I995 E I998

\begin{tabular}{l|r|r|r|r|r|r}
\hline \multirow{2}{*}{ Subsetor industrial } & \multicolumn{2}{|c|}{1991} & \multicolumn{2}{c|}{1995} & \multicolumn{2}{c}{1998} \\
\cline { 2 - 7 } & Empregos & Participação & Empregos & Participação & Empregos & Participação \\
\hline Extrativa mineral & 1 & 0,03 & 1 & 0,02 & 3 & 0,07 \\
\hline Produtos minerais não metálicos & 65 & 1,80 & 20 & 0,39 & 48 & 1,10 \\
\hline Metalurgia & 340 & 9,41 & 305 & 6,00 & 419 & 9,61 \\
\hline Mecânica & 409 & 11,32 & 719 & 14,15 & 523 & 11,99 \\
\hline Material elétrico e comunicações & 312 & 8,63 & 227 & 4,47 & 258 & 5,92 \\
\hline Material de transporte & 34 & 0,94 & 117 & 2,30 & 106 & 2,43 \\
\hline Madeira e mobiliário & 173 & 4,79 & 266 & 5,23 & 113 & 2,59 \\
\hline Papel, papelão, editoras e gráficas & 279 & 7,72 & 68 & 1,34 & 237 & 5,43 \\
\hline Borracha, fumo, couro e peles & 462 & 12,78 & 115 & 2,26 & 51 & 1,17 \\
\hline $\begin{array}{l}\text { Química, farmacêutica, } \\
\text { veterinária, perfumaria e sabão }\end{array}$ & 221 & 6,12 & 240 & 4,72 & 336 & 7,70 \\
\hline $\begin{array}{l}\text { Têxtil do vestuário e } \\
\text { artefatos de tecidos }\end{array}$ & 282 & 7,80 & 285 & 5,61 & 383 & 8,78 \\
\hline Calçados & 46 & 1,27 & 65 & 1,28 & 41 & 0,94 \\
\hline $\begin{array}{l}\text { Produtos alimentícios, } \\
\text { bebidas e álcool etílico }\end{array}$ & 990 & 27,39 & 2.655 & 52,23 & 1.843 & 42,26 \\
\hline \begin{tabular}{l} 
TOTAL INDÚstRIA \\
\hline
\end{tabular} & 3.614 & 100,00 & 5.083 & 100,00 & 4.361 & 100,00 \\
\hline
\end{tabular}

Fonte: Rais/MTb I998. 


\section{TABELA 3}

NÚMERO DE ESTABELECIMENTO, POR SUBSETOR IBGE, MUNICÍPIO DE CATANDUVA, I99I, I995 E I998

\begin{tabular}{|c|c|c|c|c|c|c|}
\hline \multirow[t]{2}{*}{ Subsetor industrial } & \multicolumn{2}{|c|}{1991} & \multicolumn{2}{|c|}{1995} & \multicolumn{2}{|c|}{1998} \\
\hline & Estabelecimento & Participação & Estabelecimento & Participação & Estabelecimento & Participação \\
\hline Extrativa mineral & 1 & 0,43 & 1 & 0,45 & 2 & 0,83 \\
\hline $\begin{array}{l}\text { Produtos minerais } \\
\text { não metálicos }\end{array}$ & 13 & 5,63 & 14 & 6,31 & 12 & 4,96 \\
\hline Metalurgia & 34 & 14,72 & 34 & 15,32 & 45 & 18,60 \\
\hline Mecânica & 12 & 4,19 & 18 & 8,11 & 13 & 5,37 \\
\hline $\begin{array}{l}\text { Material elétrico } \\
\text { e comunicações }\end{array}$ & 10 & 4,33 & 7 & 3,15 & 7 & 2,89 \\
\hline Material de transporte & 3 & 1,30 & 7 & 3,15 & 7 & 2,89 \\
\hline Madeira e mobiliário & 30 & 12,99 & 20 & 9,01 & 23 & 9,50 \\
\hline $\begin{array}{l}\text { Papel, papelão, } \\
\text { editoras e gráficas }\end{array}$ & 17 & 7,36 & 15 & 6,76 & 22 & 9,09 \\
\hline $\begin{array}{l}\text { Borracha, fumo, } \\
\text { couro e peles }\end{array}$ & 23 & 9,96 & 11 & 4,95 & 12 & 4,96 \\
\hline $\begin{array}{l}\text { Química, farmacêutica, } \\
\text { veterinária, perfumaria } \\
\text { e sabão }\end{array}$ & 13 & 5,63 & 20 & 9,01 & 25 & 10,33 \\
\hline $\begin{array}{l}\text { Têxtil do vestuário e } \\
\text { artefatos de tecidos }\end{array}$ & 37 & 16,02 & 29 & 13,06 & 36 & 14,88 \\
\hline Calçados & 11 & 4,76 & 5 & 2,25 & 5 & 2,07 \\
\hline $\begin{array}{l}\text { Produtos alimentícios, } \\
\text { bebidas e álcool etílico }\end{array}$ & 27 & 11,69 & 41 & 18,47 & 33 & 13,64 \\
\hline TOTAL INDÚSTRIA & 231 & 100,00 & 222 & 100,00 & 242 & 100,00 \\
\hline
\end{tabular}

Fonte: Rais/ MTb 1998.

O volume de emprego cresceu no início da década de 9o, mas caiu no período final. Em termos evolutivos, a queda no emprego formal no final da década deve-se especialmente à diminuição das vagas no setor processador de produtos agrícola. No setor mecânico também ocorreu essa queda; é também nessa área que se encotram as maiores empresas de Catanduva: duas usinas de álcool, uma esmagadora de frutas (laranja) e uma processadora de café. A Tabela 4 resume as atividades econômicas em Catanduva, em termos de empregos formais por subsetor. 
Porém, merecem forte atenção no município os setores de mecânica, metalurgia, material elétrico e comunicações, que representam em conjunto mais de $25 \%$ do emprego formal industrial de Catanduva, conforme mostra o Gráfico I, e por se destacar em relação ao restante do Estado de São Paulo pelo indicador de especialização (Tabela 5). Nesse setor, há a presença da produção de equipamentos de ventilação.

\section{GRÁFICO I}

\section{PARTICIPAÇÃO DOS PRINCIPAIS SETORES NO EMPREGO} INDUSTRIAL, MUNICÍPIO DE CATANDUVA, I998

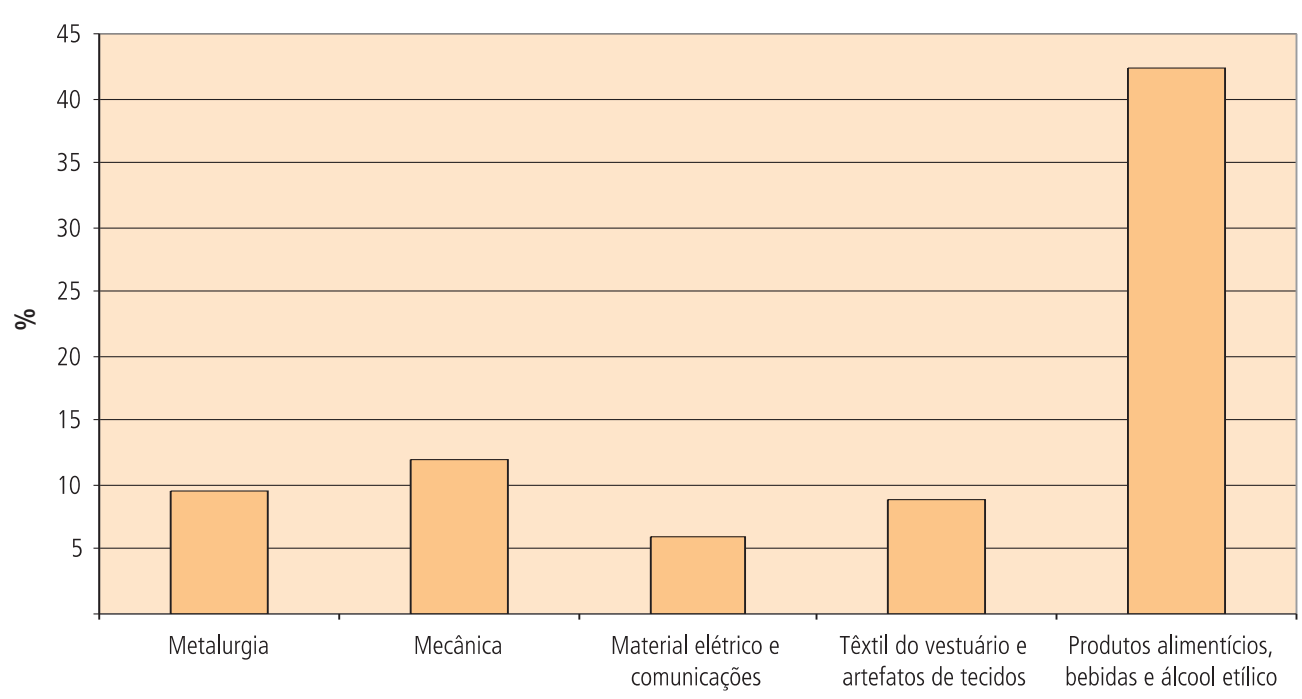

Fonte: Rais/ MTb 1998. 


\section{TABELA 4}

\begin{tabular}{|c|c|c|c|c|c|c|c|c|}
\hline \multirow{2}{*}{$\begin{array}{l}\text { Subsetor } \\
\text { industrial }\end{array}$} & \multicolumn{6}{|c|}{ Porte } & \multirow[b]{2}{*}{ Total } & \multirow[b]{2}{*}{ Participação } \\
\hline & $\begin{array}{l}0- \\
19\end{array}$ & $\begin{array}{l}20- \\
49\end{array}$ & $\begin{array}{l}50- \\
99\end{array}$ & $\begin{array}{l}100- \\
249\end{array}$ & $\begin{array}{l}250- \\
499\end{array}$ & $\begin{array}{l}500 \text { ou } \\
\text { mais }\end{array}$ & & \\
\hline Extrativa mineral & 3 & 0 & 0 & 0 & 0 & 0 & 3 & 0,07 \\
\hline $\begin{array}{l}\text { Produtos minerais } \\
\text { não metálicos }\end{array}$ & 28 & 20 & 0 & 0 & 0 & 0 & 48 & 1,10 \\
\hline Metalurgia & 165 & 154 & 0 & 100 & 0 & 0 & 419 & 9,61 \\
\hline Mecânica & 66 & 0 & 205 & 252 & 0 & 0 & 523 & 11,99 \\
\hline $\begin{array}{l}\text { Material elétrico e } \\
\text { comunicações }\end{array}$ & 22 & 133 & 0 & 103 & 0 & 0 & 258 & 5,92 \\
\hline $\begin{array}{l}\text { Material de } \\
\text { transporte }\end{array}$ & 25 & 0 & 81 & 0 & 0 & 0 & 106 & 2,43 \\
\hline $\begin{array}{l}\text { Madeira e } \\
\text { mobiliário }\end{array}$ & 113 & 0 & 0 & 0 & 0 & 0 & 113 & 2,59 \\
\hline $\begin{array}{l}\text { Papel, papelão, } \\
\text { editoras e gráficas }\end{array}$ & 78 & 22 & 0 & 137 & 0 & 0 & 237 & 5,43 \\
\hline $\begin{array}{l}\text { Borracha, fumo, } \\
\text { couro e peles }\end{array}$ & 51 & 0 & 0 & 0 & 0 & 0 & 51 & 1,17 \\
\hline $\begin{array}{l}\text { Química, } \\
\text { farmacêutica, } \\
\text { veterinária, } \\
\text { perfumaria } \\
\text { e sabão }\end{array}$ & 87 & 91 & 158 & 0 & 0 & 0 & 336 & 7,70 \\
\hline $\begin{array}{l}\text { Têxtil do vestuário } \\
\text { e artefatos de } \\
\text { tecidos }\end{array}$ & 156 & 155 & 72 & 0 & 0 & 0 & 383 & 8,78 \\
\hline Calçados & 123 & 28 & 0 & 0 & 0 & 0 & 41 & 0,94 \\
\hline $\begin{array}{l}\text { Produtos } \\
\text { alimentícios, } \\
\text { bebidas e } \\
\text { álcool etílico }\end{array}$ & 126 & 104 & 0 & 356 & 1.257 & 0 & 1.843 & 42,26 \\
\hline TOTAL INDÚSTRIA & 933 & 707 & 516 & 948 & 1.257 & 0 & 4.361 & 0 \\
\hline Participação & 21,39 & 16,21 & 11,83 & 21,76 & 28,82 & 0 & 0 & \\
\hline
\end{tabular}

Fonte: Rais/MTb I998. 


\section{TABELA 5}

\begin{tabular}{l|c|c|c}
\hline \multicolumn{3}{l}{ IN D ICAD OR DE ESPECIALIZAÇÄO, MUNICIPIO DE CATAND UVA } \\
\hline Subsetor industrial & 1991 & 1995 & 1998 \\
\hline Extrativa mineral & 0,02 & 0,02 & 0,06 \\
\hline Produtos minerais não metálicos & 0,20 & 0,06 & 0,14 \\
\hline Metalurgia & 0,67 & 0,58 & 0,80 \\
\hline Mecânica & 0,85 & 1,62 & 1,28 \\
\hline Material elétrico e comunicações & 1,17 & 0,91 & 1,08 \\
\hline Material de transporte & 0,07 & 0,27 & 0,25 \\
\hline Madeira e mobiliário & 0,72 & 1,08 & 0,43 \\
\hline Papel, papelão, editoras e gráficas & 1,16 & 0,26 & 0,88 \\
\hline Borracha, fumo, couro e peles & 1,38 & 0,44 & 0,21 \\
\hline Química, farmacêutica, veterinária, perfumaria e sabão & 0,50 & 0,50 & 0,68 \\
\hline Têxtil do vestuário e artefatos de tecidos & 0,38 & 0,41 & 0,63 \\
\hline Calçados & 0,17 & 0,29 & 0,22 \\
\hline Produtos alimentícios, bebidas e álcool etílico & 0,97 & 2,15 & 1,78 \\
\hline TOTAL INDÚstRIA & 0,67 & 0,94 & 0,86
\end{tabular}

Fonte: Rais/ MTb I998.

I) O indicador de especialização do município - revelando a participação de cada setor em relação ao interior do Estado, ponderando-se pelo tamanho do município - apresenta a importância de cada setor relativamente aos demais municípios do interior de São Paulo (Total do Estado menos Região Metropolitana). Um indicador de especialização próximo a I revela que a participação do setor seria equivalente à média do interior. Quanto maior o indicador, maior o nível de especialização do município em relação à questão.

2) O cálculo do indicador é feito dividindo-se a relação entre o emprego formal do setor i no município j e o emprego formal total do município pela relação entre o setor i no interior do Estado e o emprego total no interior do Estado. 


\section{TABELA 6}

\section{NÚMERO DE ESTABELECIMENTOS, POR SUBSETOR, SEGUNDO O TAMANHO DO ESTABELECIMENTO, MUNICÍPIO DE CATANDUVA, I99 8}

\begin{tabular}{|c|c|c|c|c|c|c|c|c|}
\hline \multirow{2}{*}{$\begin{array}{l}\text { Subsetor } \\
\text { industrial }\end{array}$} & \multicolumn{6}{|c|}{ Porte } & \multirow{2}{*}{ Total } & \multirow{2}{*}{ Participação } \\
\hline & $\begin{array}{l}0- \\
19\end{array}$ & $\begin{array}{l}20- \\
49\end{array}$ & $\begin{array}{l}50- \\
99\end{array}$ & $\begin{array}{l}100- \\
249\end{array}$ & $\begin{array}{l}250- \\
499\end{array}$ & $\begin{array}{c}500 \text { ou } \\
\text { mais }\end{array}$ & & \\
\hline Extrativa mineral & 2 & 0 & 0 & 0 & 0 & 0 & 2 & 0,83 \\
\hline $\begin{array}{l}\text { Produtos minerais } \\
\text { não metálicos }\end{array}$ & 11 & 1 & 0 & 0 & 0 & 0 & 12 & 4,96 \\
\hline Metalurgia & 39 & 5 & 0 & 1 & 0 & 0 & 45 & 18,60 \\
\hline Mecânica & 8 & 0 & 3 & 2 & 0 & 0 & 13 & 5,37 \\
\hline $\begin{array}{l}\text { Material elétrico e } \\
\text { comunicações }\end{array}$ & 2 & 4 & 0 & 1 & 0 & 0 & 7 & 2,89 \\
\hline $\begin{array}{l}\text { Material de } \\
\text { transporte }\end{array}$ & 6 & 0 & 1 & 0 & 0 & 0 & 7 & 2,89 \\
\hline $\begin{array}{l}\text { Madeira e } \\
\text { mobiliário }\end{array}$ & 23 & 0 & 0 & 0 & 0 & 0 & 22 & 9,50 \\
\hline $\begin{array}{l}\text { Papel, papelão, } \\
\text { editoras e gráficas }\end{array}$ & 20 & 1 & 0 & 1 & 0 & 0 & 23 & 9,09 \\
\hline $\begin{array}{l}\text { Borracha, fumo, } \\
\text { couro e peles }\end{array}$ & 12 & 0 & 0 & 0 & 0 & 0 & 12 & 4,95 \\
\hline $\begin{array}{l}\text { Química, } \\
\text { farmacêutica, } \\
\text { veterinária, } \\
\text { perfumaria e sabão }\end{array}$ & 20 & 3 & 2 & 0 & 0 & 0 & 25 & 10,33 \\
\hline $\begin{array}{l}\text { Têxtil do vestuário } \\
\text { e artefatos } \\
\text { de tecidos }\end{array}$ & 31 & 4 & 1 & 0 & 0 & 0 & 36 & 14,88 \\
\hline Calçados & 4 & 1 & 0 & 0 & 0 & 0 & 5 & 2,07 \\
\hline $\begin{array}{l}\text { Produtos } \\
\text { alimentícios, } \\
\text { bebidas e álcool } \\
\text { etílico }\end{array}$ & 24 & 3 & 0 & 2 & 4 & 0 & 33 & 13,64 \\
\hline TOTAL INDÚSTRIA & 202 & 22 & 7 & 7 & 4 & 0 & 242 & 100,00 \\
\hline Participação & 83,47 & 9,09 & 2,89 & 2,89 & 1,65 & 0,00 & 100,00 & \\
\hline
\end{tabular}

Fonte: Rais/ MTb 1998. 
Catanduva é conhecida como a capital brasileira do ventilador. A cidade possui diversas empresas direta ou indiretamente ligadas à produção do produto. Destacam-se a Loren Sid, a Tron e a Venti-Delta, empresas líderes. Outras, menores, também produzem o bem final e existem várias outras associadas que componentes.

A Loren Sid, por exemplo, é a maior empresa de ventiladores do País, responde por $25 \%$ da produção nacional. A ela estão associadas quatro outras empresas vinculadas, cada uma produzindo uma parte do ventilador, para a Loren Sid e também para as indústrias concorrentes.

No município, produzem-se praticamente todos os componentes do produto, com exceção das pás de madeira (trazidas, principalmente, da região norte do Brasil). O resto da matéria-prima - chapa de aço, fio de cobre - vem da capital do Estado de São Paulo, mas a partir de então tudo é feito no município, constituindo-se este um dos elementos na definição de cluster. Existem fábricas especializadas na galvanização, outras na produção dos lustres que vão acoplados ao ventilador e ainda fabricantes de capacitadores. Alguns serviços são feitos dentro das próprias indústrias ou ainda por trabalhadores informais em suas casas. Há muitas mulheres em Catanduva que enrolam os motores dos ventiladores. Esse serviço é utilizado por algumas indústrias. Outras preferem internalizar o processo, em função de a atividade das mulheres ser informal.

A produção de Catanduva atinge $90 \%$ do mercado nacional. A estimativa do tamanho de mercado para os ventiladores de teto, que é a especialidade dos produtores de Catanduva, é de cinco milhões de unidades por ano. A exportação, contudo, corresponde a menos de I\% do total produzido. Atualmente, as exportações são dirigidas ao Mercosul e à Bolívia. Havia uma expectativa de melhora dessas exportações com a desvalorização da moeda nacional, mas as incertezas que envolvem o mercado internacional impossibilitaram a concretização desse projeto. A Tron chegou a fazer contato com empresa especializada para que fosse feito um estudo de viabilidade e uma estratégia de ação exportadora, mas o preço cobrado foi, na avaliação da indústria, alto demais para que o contrato pudesse ser fechado individualmente.

As empresas são na sua maioria familiares. A origem desse setor se deu em meados do século XX, com a instalação da primeira fábrica na região. Depois disso, as outras companhias que surgiram, na sua grande maioria, foram constituídas por pessoas da região anteriormente ligadas ao setor. Eram funcionários da empresa inicial que saíram dela e constituíram seu próprio negócio. Esse processo se repetiu no último meio século, com funcionários ou sócios saindo de uma empresa e se estabelecendo em novas unidades; a maior parte na produção de componentes, pelo menos no início, mas algumas poucas também produzindo o bem final.

Apesar de a cidade ser naturalmente uma formadora de mão-de-obra no setor, há, muitas vezes, dificuldade em achar profissionais capacitados para preencher 
as vagas oferecidas pelas indústrias. Existe na verdade uma incompatibilidade entre os cursos oferecidos pela escola estadual técnica e profissionalizante Elias Nechar (ligada à Fundação Paula Sousa) e as demandas das indústrias. A colocação de pessoas no mercado de trabalho enfrenta alguns obstáculos: um é justamente falta de treinamento e capacitação específica adequados e o outro diz respeito ao nível de escolaridade. Neste último caso, o mais comum é encontrar empregos que exijam o segundo grau completo, e apenas uma minoria dos que procuram empregos na indústria o possui.

Outro problema é a sazonalidade da produção, em função da concentração das vendas no verão. A saída é a ampliação do mercado consumidor em período diferente, especialmente por meio das exportações e da diversificação da produção.

Algumas das empresas ligadas à produção de ventiladores de teto estão em distritos industriais do município. Em Catanduva existem quatro distritos industriais, dois deles com alguns problemas, como a presença de residências e comércio, alguns lotes vazios e outras fábricas desativadas. Apesar das dificuldades, os bairros são nitidamente industrias e certamente esses distritos obtiveram algum êxito em seus propósitos. Os distritos industriais se resumem a regiões destinadas à localização de empresas. Pouco se aproveita nessas localidades da possibilidade de haver práticas conjuntas das empresas ali localizadas. Não exploram, por exemplo, a possibilidade de compras conjuntas ou fornecimento de alimentação e transporte para os empregados, práticas que poderiam reduzir custos ou aumentar a eficiência das empresas.

Tomando por base os elementos anteriormente apresentados, o setor de ventiladores de teto em Catanduva possui várias características que permitem defini-lo como um cluster. Sem dúvida muitas ações deveriam ser implementadas com o objetivo de aumentar sua competitividade, em particular no que diz a esforços conjuntos destacados anteriormente.

Pode-se observar a seguir, segundo a Tabela 7, de que maneira as características do setor de ventiladores de Catanduva tendem a permitir classificá-lo como um cluster. Diversas características apresentadas pelos autores citados anteriormente podem ser encontradas no setor de produção de ventiladores em Catanduva. Em razão da proximidade das empresas dedicadas ao setor, podem-se destacar aspectos característicos do cluster, como dinâmica de mercado, economias de custos de coordenação, eficiências de custos de produção, concorrência estimulada, comunicação entre fornecedores e clientes, surgimento de novos concorrentes por meio de funcionários de empresas pioneiras, especialização das empresas em partes da produção com ganhos de escala (Tabela 7).

No entanto, destacam-se em Catanduva alguns aspectos a serem aprimorados no sentido de aumentar a competitividade do cluster. O setor apresenta inte- 
resse em que haja investimentos em formação e educação, sendo uma oportunidade de apoio governamental em particular. No aspecto eficiência coletiva, notase a oportunidade de criação de consórcio de empresas de ventiladores. Alguns desses aspectos identificados na pesquisa são destacados no próximo item.

\section{TABELA 7}

\section{CONFRONTAÇÃO DO PERFIL DO SETOR DE VENTILADORES DE CATANDUVA COM AS CARACTERÍSTICAS DE UM CLUSTER}

\begin{tabular}{|c|c|c|}
\hline Características & Cluster & Catanduva \\
\hline Mão-de-obra & Disponível na região & Desenvolver centros de capacitação \\
\hline Tecnologia & $\begin{array}{l}\text { Desenvolvida por meio de } \\
\text { parcerias entre empresas }\end{array}$ & As empresas têm um certo grau de interação \\
\hline Tipo de coordenaçãa & Dinâmica de mercado & $\begin{array}{l}\text { Diferentes empresas compartilham atividades } \\
\text { de produção na cadeia de valor }\end{array}$ \\
\hline Custos de coordenação & $\begin{array}{l}\text { Apesar da dinâmica de mercado, tendem a } \\
\text { ser reduzidos em razão da proximidade e } \\
\text { intimidade desenvolvida entre os parceiros } \\
\text { (fornecedores e clientes) }\end{array}$ & $\begin{array}{l}\text { A proximidade entre fabricantes de } \\
\text { diferentes componentes dos ventiladores } \\
\text { em Catanduva permite observar economias } \\
\text { de custos de coordenação }\end{array}$ \\
\hline Custos de produção & Maior eficiência & $\begin{array}{l}\text { As empresas têm-se mantido eficientes com } \\
\text { controle satisfatório de custos em particular em } \\
\text { razão da proximidade entre empresas produtoras }\end{array}$ \\
\hline Exposição a forças competitivas & Maior & $\begin{array}{l}\text { A concorrência é estimulada na comercialização } \\
\text { de ventiladores, uma vez que Catanduva produz } \\
90 \% \text { dos ventiladores no Brasil }\end{array}$ \\
\hline Impacto nos preços & $\begin{array}{l}\text { Os preços tendem a ser menores em razão da } \\
\text { concorrência entre empresas no cluster }\end{array}$ & Não foi objeto da pesquisa \\
\hline Comunicação com fornecedores e clientes & Facilitada pela comunicação pessoal & $\begin{array}{l}\text { As empresas interagem bastante em } \\
\text { razão da proximidade }\end{array}$ \\
\hline Apoio governamental & $\begin{array}{l}\text { Estimulado por se tratar de investimentos } \\
\text { em uma região econômica }\end{array}$ & $\begin{array}{l}\text { Ações como incentivo à criação de centros } \\
\text { de formação poderiam ser implementadas. }\end{array}$ \\
\hline Investimentos em formação e educação & Compartilhado pelas diversas empresas & $\begin{array}{l}\text { São poucos atualmente, sendo, no } \\
\text { entanto, uma oportunidade }\end{array}$ \\
\hline Surgimento de novos concorrentes & $\begin{array}{l}\text { Facilitado em função da possibilidade de atração } \\
\text { de pequenos empresários especializados }\end{array}$ & $\begin{array}{l}\text { Funcionários das empresas pioneiras } \\
\text { criaram a concorrência local. }\end{array}$ \\
\hline Eficiência coletiva & $\begin{array}{l}\text { Obtida por meio de ações de cooperação entre } \\
\text { empresas }\end{array}$ & $\begin{array}{l}\text { Oportunidade de criação de um } \\
\text { consórcio de empresas de ventiladores }\end{array}$ \\
\hline Economias de escala & $\begin{array}{l}\text { Tanto na exploração de um mercado mais } \\
\text { extenso, quanto no compartilhamento de } \\
\text { maquinário e outros fatores de produção }\end{array}$ & $\begin{array}{l}\text { As diversas empresas se especializam } \\
\text { em partes da produção de ventiladores, } \\
\text { obtendo-se uma economia que não seria } \\
\text { encontrada individualmente; por exemplo, } \\
\text { as fábricas especializadas em galvanização, } \\
\text { ou de lustres acoplados ao ventilador }\end{array}$ \\
\hline
\end{tabular}




\section{CONSIDERAÇÕES PARA \\ MELHORIA DA COMPETITIVIDADE dO CLUSTER dE CATANDUVA}

Confirmada a viabilidade de caracterização do setor de ventiladores de Catanduva como um cluster, o estudo realizado para esta pesquisa permite ir além da constatação e identificar oportunidades de melhoria de competitividade desse cluster.

Como há também um potencial de expansão do setor em Catanduva, especialmente em termos externos, a pergunta que parece interessante ser feita é: a fim de que esse potencial se realize e para que as vantagens e os benefícios da organização em forma de cluster sejam obtidos, quais ações poderiam ser executadas?

Com base nas avaliações feitas, pode-se relacionar um conjunto de possibilidades que contemplam essas linhas gerais de atuação, detalhadas a seguir:

a) reforço das economias de aglomeração;

b) desenvolvimento tecnológico e aprimoramento da qualificação dos profissionais do setor; e

c) busca de novas estratégias de comercialização e consolidação da reputação.

Observou-se que, dentro do setor de ventiladores, é importante estar atento à contínua manutenção de níveis tecnológicos atualizados, assim como à manutenção de processos e procedimentos industriais de baixo custo, para a evitar a perda dos mercados já conquistados e ampliar seus próprios mercados. A qualificação dos empregados também se mostra um elemento importante nesse sentido e parece claro haver um problema no município, como destacado no levantamento realizado neste estudo, de adequação das atividades de qualificação profissional às demandas do setor industrial.

A cooperação entre empresas de um cluster se apresenta como um fator importante (GEINDRE, 200I). Ação que parece importante é a criação de um consórcio das empresas de ventiladores de Catanduva, a exemplo do que ocorre em outros setores, tanto com o intuito de fortalecer a marca da própria cidade como principal produtora dessa mercadoria, quanto também com vistas a dinamizar as vendas, em especial no mercado externo, e continuar desenvolvendo tecnologia. Dentro desse consórcio, seria possível estabelecer parcerias negociadas, a fim de desenvolver ações de marketing e busca de novos mercados de maneira conjunta, bem como de montagem e desenvolvimento de projetos industriais complementares. A exportação poderia diminuir o problema da sazonalidade do setor, que marca a indústria de ventiladores.

A obtenção de selos, certificados de qualidade e de denominação de origem também é importante na manutenção e ampliação do mercado dessas empresas e na consolidação do município como centro produtor de ventiladores. Uma 
possibilidade que deveria ser explorada é a de atração ou criação de atividades complementares à atividade básica, reforçando a competitividade do cluster. Tanto no fornecimento de parte dos produtos, como em produtos complementares, é possível diversificar a atividade principal, e, especialmente no caso de atividades complementares, a possibilidade de trabalhar com vendas casadas é bastante rentável e ainda não totalmente explorada.

Pode-se observar, por meio dos levantamentos efetuados, que um ponto importante nesta área é a organização do setor informal que presta serviço às indústrias - principalmente das mulheres que trabalham na montagem do motor. Além de aumentar o poder de barganha dessas trabalhadoras, a legalização da atividade poderia representar uma expansão do mercado potencial dos serviços prestados.

Parecem importantes ações municipais, no sentido de recuperar os distritos industriais, buscando-se ganhos de aglomeração.

\section{CONCLUSÕES}

Este trabalho procurou identificar a existência de um cluster de ventiladores na cidade de Catanduva, no interior do Estado de São Paulo, por meio da definição do conceito de cluster na literatura. A configuração, em cluster, desse setor em Catanduva apresenta qualidades que estimulam o interesse na sua evolução, a exemplo de outros clusters no País.

O trabalho de campo permitiu também notar que é um setor importante na região e que os pontos fracos, tais como formação de mão-de-obra, devem ser corrigidos para que a área possa se desenvolver, em particular do ponto de vista de exportação. O desenvolvimento das exportações é um elemento potencial importante para a região, uma vez que reduz o problema de sazonalidade que sofre, evidentemente, uma indústria de ventiladores.

Outras pesquisas poderiam explorar mais profundadamente os itens apresentados na Tabela 7, procurando avaliar as possibilidades de desenvolvê-los.

\section{REFERÊTCIAS}

ANDRESTSCH, D. B. Agglomeration and the location of innovative activity. Oxford Revie of economic policy, Summer, v. I4, n. 2, I998.

ALTENBURG, T.; MEYER-STAMER, J. How to promote clusters: experiences from Latin America. World Development 27 (9), I999.

AMATO NETO, J. Redes de cooperação produtiva e clusters regionais: oportunidades para pequenas e médias empresas. São Paulo: Atlas, 2000.

CAMAGNI, R. P. (Ed.) Innovation networks: spatial perspectives. Londres: Belhaven, I99I. 
COMPETITIVENESS INSTITUTE. Disponível em: <http://www.competitiveness.org/>. Acesso em: 25 fevereiro 200 I.

CONEJOS, J. et al. Cambio estratégico y clusters en Cataluna. Barcelona: Gestión 2000, I997.

ENRIGHT, M. J. Why local clusters are the way to win the game. World Link 5, p. 24-25, Jul.-Aug., I992. . The geographic scope of competitive advantage. In: DIRVEN, E.; GROENEWEGEN, J.; VAN HOOF, S. (Eds.). Stuck in the region? Changing scales of regional identity. Netherlands Geographical Studies I55, p. 87-102, I993.

GRAINO, A. Galicia una comunidad autónoma que afronta com garantías el futuro. Negócios, 24 mar. 1998 .

GEINDRE, S. La mise en place d'un réseau stratégique au sein d'un district industriel. Actes du colloque sur les rélations industrielles Franco-Brésiliennes, Ecóle Supérieure des Affaires, UPMF-Grenoble, 29 e 30 mars, p. 269-287, 2001.

HAKANSSON, H. The network as a governance structure; interfirm co-opperation beyond markets and hierarquies. In: GRABHER G. (Ed.). The embebed firm: on the socio-economics of industrial networks. Londres: Routledge, I993.

HANSEN, N. Competition, trust and reciprocity in the development of innovative regional milieux. Pap. Reg. Sci 7I, p. 95-105, I992.

KAMANN, D. J. F. Modelling networks: a long way to go. Tijdschr. Econ. Soc. Geogr. 89, p. 279297, 1998.

McCORMICK, D. Enterprise clusters in Africa: on the way to industrialization? IDS Discussion Paper, n. 366. Institute of Development Studies, University of Sussex, Brighton, I998.

NOOTEMBOOM, B. Towards a dynamic theory of transactions. J. Evolutionary Economy, n. 2, p. 49I-503, I992.

PORTER, M. E. Clusters and the new economics of competition. Harvard Business Review, p. 7790, nov./dec. I998.

. Aglomerados e competição. Competição - Estratégias competitivas essenciais. Rio de Janeiro: Campus, I999.

. Ser competitivo. Harvard DEUSTO Business Review, n. II88, p. 34-37, I999.

SCHMITZ, H. Collective efficiency: growth path for small-scale industry. Journal of Development Studies, v. 3I, n. 4, I995.

. Collective efficiency and increasing returns. IDS Working Paper, n. 50, Institute of Fevelopment Studies, University of Sussex, Brighton, March, I997.

Clustering and industrialization: introduction. World Development 27 (9), I999.

SCOTT, A. The geographic foundations of industrial performance. In: CHANDLER JR., A; HAGSTROM, P.; SOLVELL, O. (Eds.). The dynamic firm - The role of technology, organization and regions. Oxford: Oxford University Press, I998.

SFORZI, F. The quantitative importance of Marshallian industrial districts in the italian economy. In: PYKE et al., 75-I07, I992.

SUZIGAN, W.; FURTADO, J.; GARCIA, R.; SAMPAIO, S. Aglomerações industriais no estado de São Paulo. Anais do XXVIII Encontro Nacional de Economia. Campinas: ANPEC, 2000.

WEVER, E.; STAM E. Clusters of higher technology SMEs: The Dutch case. Regional Studies, v. 33, n. 4, p. 39I-400, Jun. I999.

\section{TR A MITAÇ Ã O}

Recebido em 25/03/2004

Aprovado em 28/10/2004 